\title{
Teoría y práctica de la ética en el siglo XXI (Undécimas Conferencias Aranguren, 2002)
}

\author{
VICTORIA CAMPS \\ Universidad Autónoma de Barcelona
}

\begin{abstract}
RESUMEN. La vinculación entre la teoría ética y la práctica moral es uno de los problemas recurrentes de la filosofía moral, más acuciante en el escenario producido por el liberalismo económico, moral y político. Los tres apartados en que se divide el artículo se refieren a tres cuestiones que, a juicio de la autora, causan desconfianza y escepticismo con respecto a la teoría ética contemporánea. En primer lugar, la imposibilidad de construir una moralidad pública en las sociedades laicas y plurales. Segundo, la falta de atención que las teorías suelen prestar al problema de la motivación moral. Finalmente, el peligro que representan hoy los fanatismos y los fundamentalismos morales y políticos. Los tres apartados tienen que ver con un tema nuclear en la ética de nuestro tiempo: el ejercicio de la libertad en las democracias actuales.
\end{abstract}

ABSTRACT. This paper deals with the difficult link between ethical theory and moral practice. It is a recurrent problem of moral philosophy specially worsed because of the spread of economic, social and political liberalism. The three parts of the paper deal with three questions which, from the point of view of the author, bring abaut mistrust and scepticism about contemporary ethics. The first questions is the difficulty of constructing a public morality within our secular and plural societies. The second one refers to the little attention payed by ethical theories to the problem of moral motivation. The last question raise the problem represented nowadays by fanatism and fundamentalism. All three parts have to deal with a further question which lays at the core of contemporary ethics: the exercise of liberty in liberal democracies.

Desde Aristóteles, la realización práctica de la teoría ética es un problema que concierne a la filosofía. «No nos interesa qué es la virtud sino ser virtuosos», se repite con insistencia en la Ética a Nicómaco. ¿Cómo es posible que la razón pura sea práctica? o ¿cómo es posible que la razón moral obligue?, se pregunta Kant al concluir la Fundamentación de la metafísica de las costumbres. La preocupación de Kant no impide que la ética formal y a priori kantiana sea criticada por los utilitaristas por ser excesivamente pura y desarraigada, por su fracaso a la hora de incidir en las reformas legislativas, que es lo que busca Bentham. En nuestro tiempo, las réplicas y críticas comunitaristas, e incluso republicanas, al liberalismo se apoyan en el argumento de que el individualismo abstracto liberal carece de fuerza prescriptiva: sus 
principios son demasiado abstractos y el sujeto al que se dirigen no está en ninguna parte, de forma que difícilmente se sentirá motivado a actuar de acuerdo con los derechos y deberes que se le adjudican.

Dicha preocupación, siendo como es implícita al discurso moral, y quizá irremediable, adquiere en cada época tintes distintos. Las razones por las que una determinada teoría ética nos parece irrealizable, o poco motivadora, tienen que ver con problemas específicos de cada momento histórico. Lo que me propongo hacer aquí es reflexionar sobre algunas de las circunstancias de nuestro tiempo que provocan conflictos especialmente acuciantes y que nos conducen a contemplar con escepticismo el discurso moral, como un discurso bello en teoría pero demasiado alejado de la realidad. Los tres capítulos que siguen responden a tres de los problemas que llevan a desconfiar de la ética y de su capacidad para mover a la acción.

1. El primero de ellos tiene que ver con el rechazo de lo que podríamos denominar una moralidad pública, que hasta hace poco permaneció vinculada a una religión o a una ideología determinadas (y en algunos lugares sigue estándolo, allí precisamente donde el liberalismo brilla por su ausencia). De tal rechazo deriva una deficiente articulación de los derechos y obligaciones morales en torno al uso de la libertad. Una libertad que ha acabado siendo pura libertad negativa y que conduce asimismo a separar radicalmente los deberes de la justicia - universalizables - y el ideal de la felicidad o de la vida buena - que es particular.

2. El segundo problema es el de la falta de motivación moral, que aunque es endémica y siempre ha merecido la atención de los filósofos, parece ir en aumento a medida que se extienden la sociedad de consumo y los valores económicos y estrictamente hedonistas. El escepticismo moral crece y, en muchos casos, tal crecimiento se quiere explicar por la pérdida de un fundamento religioso o trascendente para la moral. Desde dicho escepticismo, parece difícil o imposible que el individuo pueda forjarse una identidad moral mínimamente fuerte y sólida.

3. Finalmente, y puesto que los dos problemas anteriores tienen que ver con el hecho de que la secularización de la moral no se ha logrado del todo $\mathrm{y}$, si se ha logrado, ha sido a costa de unas deficiencias para las que no se encuentra remedio, el tercer problema que me propongo abordar es el del fanatismo o los fundamentalismos. No puede decirse que el fanatismo sea una actitud inmoral, sino que tal vez es la respuesta a una desmoralización imparable. Puesto que las consecuencias del fanatismo nos están afectando tanto a todos, pienso que la filosofía moral no puede eludir el enfrentarse a sus raíces y consecuencias. 


\section{LA AUSENCIA DE UNA MORALIDAD PÚBLICA}

¿Cuál es el lugar de la moral en las democracias liberales? ¿Cómo se forja la moralidad en el seno del liberalismo? La pregunta tiene que ver sobre todo con un fenómeno de doble cara que se está dando en nuestras sociedades: por un lado, hay una demanda de moral inédita hasta el momento; por otro, se percibe más que nunca la ausencia de moral o la acumulación de inmoralidades. Es posible que la explicación de la demanda moral sea la ausencia de ideologías fuertes, sean religiosas o laicas. El fracaso del comunismo y la aceptación del pluralismo religioso nos dejan, en efecto, sin asideros que nos orienten con respecto a qué debemos hacer. En cuanto a la sensación de que la moral está ausente, puede que no sea de hecho una ausencia mayor que la habida en otros tiempos, quizá la percepción de que el mundo se vuelve más inmoral tenga algo que ver con la extensión de la democracia y, por lo tanto, de algo más de transparencia y de control. Con una sociedad que se vuelve y se muestra más exigente y más reflexiva sobre sus faltas. Sea como sea, el hecho es que hoy andamos faltos de moral y no sabemos muy bien dónde ir a buscar lo que nos falta.

Ese sentimiento ambivalente, si no lo remediamos tratando de delimitar el espacio que debe ocupar la moral en nuestro mundo, puede llevarnos $-\mathrm{y}$ creo que, de hecho, nos está llevando ya - a la disolución inevitable de la moral en Derecho o en política. Si es cierto, como afirman muchos filósofos contemporáneos y en especial John Rawls, que el valor básico de las sociedades bien ordenadas es la justicia, y que el sujeto de la justicia son las instituciones políticas y no los ciudadanos a título individual, no es extraño que, en tales sociedades, el individuo tienda a sentirse cada vez más descargado de la obligación de construir un bien común. Ése será, en definitiva, el deber de los poderes públicos, del Derecho positivo, que son las instancias que deben garantizar el respeto a los derechos fundamentales. La juridificación de todos los discursos, incluido el moral, es un peligro de nuestro tiempo contra el que hay que defenderse.

\section{a) El bien común como generalización de los bienes privados}

Me he referido a Rawls como uno de los culpables de la reducción de la moral a Derecho o a política, porque creo que ese peligro deriva - como decía hace un momento - de una separación excesiva y poco fundada entre eso que ha venido en llamarse la justicia y lo que se describe, a su vez, como vida buena. ¿Es cierto que son dos ámbitos separados y que uno es libre mientras el otro debe construirse en común? ¿No es más cierto que la justicia se forma siempre a partir de la generalización de las distintas nocio- 
nes de vida buena, en cuyo caso la obligación moral del ciudadano sería velar por que sus concepciones del bien no acaben siendo contrarias con los mínimos de la justicia? Son dos hipótesis que creo válidas como punto de partida para abordar el problema de este primer apartado.

La tesis rawlsiana de que el sujeto de la justicia son las instituciones políticas parece abandonar al individuo al disfrute puro y simple de la libertad negativa, tal como la define Isaiah Berlin: una libertad que debe ir cediendo el Estado, que consiste en la ausencia de coacción, y de la que cada cual puede gozar a su aire. Es la definición de libertad como ausencia de leyes, tal como la entendieron, entre otros, Montesquieu o Bentham. Es decir, una sociedad justa obliga a los ciudadanos a respetar la libertad de los demás, al tiempo que obliga asimismo a todos a tributar, en la medida de sus posibilidades, a favor de una mínima igualdad de oportunidades. Más allá de esas obligaciones (en absoluto despreciables, todo hay que decirlo), no debe haber ninguna presión pública sobre las opciones de libertad de las personas. Éstas son libres de vivir como les plazca: libres de decidir qué modelo de familia prefieren, libres de elegir cómo y cuándo les conviene tener hijos (ahora las técnicas reproductivas permiten todas las posibilidades), libres de decidir el momento de la muerte o incluso de sacrificar la propia vida en nombre de unas creencias religiosas (los testigos de Jehová lo hacen). Todo eso lo permite la libertad liberal o libertad negativa.

No sería del todo justo, sin embargo, imputarle sólo a Rawls ese anclaje de la teoría política socioliberal en la libertad negativa. A medida que Rawls ha ido escuchando a sus críticos, se ha apeado de algunas de sus ideas, y ya no se muestra tan estricto en la separación entre la justicia y la vida buena. Al contrario, admite una complementariedad entre ambos mundos. Ahora bien, lo hace transitando de la justicia al bien, y no al revés: a la justicia le corresponde apoyar estilos de vida dignos, es decir, reforzar aquellas concepciones del bien que ya están incluidas en la concepción política de la justicia. ¿Cuáles son esas maneras de vivir?

En «La primacía de lo justo», uno de los capítulos de El liberalismo político, responde a la pregunta. Son maneras dignas de vivir: a) las ideas compartidas por todos los ciudadanos; $b$ ) las maneras no basadas en una doctrina comprehensiva (metafísica, moral o religiosa). Es decir, hay convicciones sobre lo bueno que han acabado universalizándose, por lo menos, en el territorio de un Estado de Derecho. Esas convicciones pasan a integrar, desde entonces, el ámbito de lo justo. Así ocurrió en Estados Unidos con la abolición de la esclavitud. No sería legítimo aceptar, en el siglo XXI, la esclavitud como forma de vida preferible por algún ciudadano. Otras opciones de vida buena, por el contrario, no son generalizables, puesto que es evidente que están amparadas por una determinada teoría comprehensiva. Es lo que ocurre con la convicción de que la procreación es el único fin del matrimonio, la condena de la homosexualidad, la maximización utilitarista del bienestar, la 
definición del hombre como animal político o cualquier otro ideal de perfección humana religioso o ideológico. Así expuesta, la teoría parece clara, pero deja de serlo si nos fijamos en un ejemplo como el de la pena de muerte. ¿Por qué no es universalizable en pleno siglo XXI y en el país más poderoso de la tierra? ¿Habrá que reconocer que el rechazo de la pena de muerte como una forma de vida indigna también pende de una teoría comprehensiva? ¿No puede decirse, entonces, que lo mismo ocurría con los abolicionistas en el siglo XIX, que su visión de la esclavitud era metafísica o ideológica? En conclusión, da la impresión de que Rawls no tiene otro criterio para considerar una noción del bien como justa que el de la aceptación histórica y generalizada de la misma. ¿No habría que derivar de tal conclusión que lo que conviene, entonces, es discernir qué concepciones del bien son moralmente aceptables puesto que de ellas deriva el sentido que acabaremos dándole a la justicia?

Me temo, sin embargo, que Rawls rechazaría una justicia fundada en el consentimiento universal. Su teoría es a priori trascendental, como la kantiana. Los llamados por él «bienes primarios» son aquellos que los ciudadanos no pueden dejar de querer porque son fruto del contracto en la posición original, no son consecuencia de la regla de la mayoría. Recordemos que la bestia negra de Rawls, contra quien va dirigida su teoría de la justicia, es el utilitarismo. No es de extrañar, pues, que la lista de bienes primarios coincida punto por punto con los principios de la justicia: son los mismos principios con otra formulación. Son los bienes que dan contenido a la justicia política, la cual se refiere a los derechos, libertades y oportunidades básicos. Son bienes, pues, que responden a una concepción política de la persona como sujeto de derechos y deberes, no a los deseos o aspiraciones que los individuos libremente puedan querer satisfacer que es lo que intuitivamente se incluiría en el ámbito de la vida buena. Los bienes básicos son todos aquellos requisitos por los que somos iguales. Es decir, las condiciones que necesitamos para el ejercicio o el disfrute de la libertad liberal o libertad negativa.

Ahora bien, si existen unos bienes básicos, ¿podemos afirmar, al mismo tiempo, la neutralidad del Estado respecto a la vida buena? Los principios de la justicia obligan a una serie de intervenciones públicas en las libertades individuales, obligan asimismo a una cierta cooperación y solidaridad de los ciudadanos para el mantenimiento de los bienes básicos. Es más, el liberalismo político afirma que ciertas formas de carácter o de vida moral son claramente superiores a otras, pues es preciso que el individuo o el ciudadano adquiera ciertas virtudes y desarrolle un cierto carácter o personalidad moral. Esas virtudes serían la cooperación, la civilidad, la tolerancia, la razonabilidad.

Es decir, los ingredientes para que la construcción del bien común no sea una tarea exclusiva de las instituciones políticas, que discurra casi a las espaldas de las opciones de vida del individuo, esos ingredientes - digoRawls no los ignora. Pero los considera una consecuencia del acuerdo 
- contrafáctico, no se nos olvide - con respecto a los principios de la justicia. Viene a decir, pues, que basta que se institucionalicen tales principios para que el ciudadano vaya adquiriendo las virtudes liberales. Sabemos, por el contrario, que tal concatenación o consecuencia no suele darse. No se da, en primer lugar, porque los principios de la justicia dejan bastante que desear en la práctica, se expresan y aplican imperfectamente. En segundo lugar, no es cierto que por sí solos, y habida cuenta su imperfección (que conduce antes a la descreencia que a confiar en ellos), los meros principios de la justicia eduquen a los ciudadanos en las virtudes del civismo, la cooperación o la tolerancia. La corrupción política y no política impiden ver el horizonte de justicia que la Constitución y la legislación del Estado de Derecho, sin embargo, proclaman como indiscutibles. Y, además, como sabemos desde San Pablo, la naturaleza humana es como es, tiende a pervertirse, la «carne es débil».

El mismo Rawls se plantea estas dudas, y se pregunta, en alguna ocasión, si la sociedad política debe ser sólo un medio para el bien individual, si debe abandonarse del todo el ideal de construir intencionadamente una comunidad política. Pero tiende a contestar que dicha comunidad no puede ser sino la aceptación de unas reglas del juego (así es como funcionan otras comunidades, como las orquestas o los equipos de fútbol). Basta que se siga un procedimiento. Las reglas del juego podrían variar, pero siempre dentro de un marco de mínimos, que son los principios de la justicia.

De esta forma, Rawls rechaza radicalmente el ideal de un «humanismo cívico» que, a su juicio, sería una variante del aristotelismo. El humanismo cívico deriva, a su juicio, de la definición del hombre como animal político, lo cual significa que la naturaleza humana se realiza en la participación política, que es su fin más propio. Para Rawls, afirmar que la participación política constituye la vida buena sería otra doctrina comprehensiva. Acepta, en cambio, lo que él llama «el republicanismo clásico», según el cual las virtudes políticas de los ciudadanos son imprescindibles para conservar los derechos y las libertades, si bien - y esto es lo que importa - no constituyen toda la identidad del ser humano ${ }^{1}$.

\section{b) Tendencia a diluir la moral en el Derecho}

Lo que más inquieta a Rawls es verse incluido en el grupo de los filósofos que ofrecen como teoría política lo que sólo es metafísica. Un temor plenamente justificado cuando comparamos la teoría de Rawls con la de su

${ }^{1}$ Dado que son suficientemente conocidas por el lector filósofo las teorías de Rawls expuestas hasta aquí, me he abstenido de hacer referencias concretas a su teoría de la Justicia o a El liberalismo político. La diferencia entre «humanismo cívico» y «republicanismo clásico» se encuentra en el último libro de John Rawls, La justicia como equidad. Una reformulación, Barcelona, Paidós, 2002, pp. 193-195. 
contemporáneo y colega Robert Nozick. Lo que éste pone de manifiesto, en su Anarquía, estado y utopía, es que la teoría de la justicia de Rawls es sólo una opción moral entre otras. No es que una esté mejor fundada que la otra, desde el punto de vista estrictamente filosófico, sino porque las opciones o convicciones morales de uno y otro filósofo son distintas. El simple hecho de que ambos filósofos no concluyan en la misma concepción de la justicia bastaría para deducir que ambas teorías son, en realidad, teorías metafísicas o comprehensivas.

Aceptar dicho aserto pone en cuestión la tesis kantiana de que la moral pueda ser totalmente racional y a priori de la experiencia o de las circunstancias de cada cual. Personalmente, me convence más la tesis de Hume según la cual la moral no derivaría sólo de la razón, sino de una serie de sentimientos comunes. La justicia sería, entonces, una «virtud artificial» construida, ahora sí, a partir de las ideas del bien ampliamente aceptadas. Desde una filosofía como la de Hume es más fácil llegar a la idea que trato de defender aquí: que el empeño colectivo en la construcción del bien es de fundamental importancia para el mantenimiento de la justicia y el perfeccionamiento de la misma. El mismo Kant, al rechazar la idea de un gobierno paternalista, tuvo que apoyar la de un gobierno patriótico, donde cada ciudadano estuviera comprometido con el bien de la comunidad ${ }^{2}$. Rawls se queda lejos de tal patriotismo. Hemos visto que, en su caso, el compromiso con el bien común (o la justicia) es más una obligación de las instituciones políticas que del individuo. El ciudadano no es sino el resultado de un contrato: se le garantizan sus derechos a cambio de que cumpla la ley y sea mínimamente cooperativo. Su compromiso moral con el mantenimiento y perfeccionamiento de la justicia se limita, pues, a cumplir con la legalidad. No necesita otra moral que la prescrita a través del ordenamiento jurídico.

El liberalismo político, en consecuencia, defiende una concepción más bien jurídica del ciudadano (como lo era también la de Thomas Marshall que lo entendió como sujeto de derechos civiles, políticos y sociales). De esta forma, se extiende al modelo del Estado de bienestar la teoría liberal de la «mano invisible». Si Adam Smith defendía que no era necesario moralizar a las personas porque el egoísmo privado redunda en beneficio público, la teoría del Estado de bienestar dice igualmente que no es preciso moralizar a las personas, pues ya hay instituciones que velan por una sociedad más justa, y éstas lo hacen a través de la legislación y la administración de la justicia.

No digo que la concepción del ciudadano basada en sus derechos fundamentales sea equivocada. Sólo pretendo poner de manifiesto que es insuficiente, que necesitamos algo más que comprometa a las personas con el bien

${ }^{2}$ Kant, «En torno al tópico "Tal vez eso sea correcto en teoría, pero no sirve para la práctica"», en el vol. Teoría y práctica, Madrid, Tecnos, 1986, p. 28. 
público, que las democracias no funcionan con concepciones del ciudadano meramente reivindicativas. Por eso creo que, contra la juridificación de la moral a la que acabo de referirme, se levantan, por lo menos, dos objeciones.

1) Por la fuerza coactiva que conlleva, la ley puede ser que contribuya eficazmente a mantener el orden, pero es difícil deducir que contribuya también a crear ciudadanos con más sentido moral. De la misma forma, hay que desconfiar de que el Estado de bienestar, como Estado de Derecho que incluye los derechos sociales, por sí solo, consiga que las personas adquieran un mayor sentido de la justicia. Acabemos con él, y veremos hasta cuándo se mantiene esa solidaridad que el Estado impone obligando a los ciudadanos a pagar impuestos.

Confiar en la capacidad de las instituciones políticas, y sobre todo de la ley, para hacer buenos ciudadanos es una rémora de la tradición ilustrada que cultivó esa confianza. Kant creía que la ley moral se encontraba en el corazón de cada hombre. Hoy nadie se atrevería a aventurar una afirmación tan optimista. Quizá las sociedades homogéneas, jerarquizadas, con tradiciones y referencias estables, han tenido un sentido común moral (de cuya moralidad, sin embargo, siempre conviene sospechar). Pero las sociedades heterogéneas y plurales, que son las que habitamos, carecen de otros valores comunes que no sean los económicos, como muy bien muestra el proceso de globalización. Esa carencia hace que se extienda el clamor a favor de una regulación más exigente y represora cada vez que tropezamos con un conflicto. El Derecho es la expresión de la moral mínima, esa moral a la que llamamos «justicia» y que constituye el bien común.

Los filósofos nos obstinamos en creer que entre el Derecho positivo y la justicia debe existir una relación dialéctica. La justicia debiera ser el fundamento del Derecho porque el Derecho debe ser justo. Pero la mentalidad jurídica discurre por otros derroteros: al iusnaturalismo hace años que le fue aplicada la terapia del positivismo, la cual ha calado muy hondo en la mentalidad jurídica. Según tal mentalidad, el Derecho empieza y acaba en sí mismo y debe explicarse desde dentro. La función de la ley es mantener el orden, no contribuir a la creación o al sostenimiento de un sentido moral común.

Estoy de acuerdo con la afirmación de Mary Ann Glandon de que el lenguaje de los derechos es un lenguaje políticamente $-\mathrm{y}$ sobre todo moralmente - pobre, porque no nos habla de nuestros deberes mutuos. Trata a los individuos como «extraños» entre sí ${ }^{3}$. Y lo que ocurre en las sociedades de extraños es que la ley no se ve complementada por otros discursos normativos. Así, la falta de normas sociales, el vacío moral, sólo tiende a ser cubierto con más leyes. Falta un lenguaje público de la responsabilidad, y se olvi-

\footnotetext{
${ }^{3}$ Mary Ann Glendon, Rights Talk, Nueva York, The Free Press, 1991, especialmente cap. 4.
} 
da la dimensión social (o moral) de la personalidad, que tal vez sean dos caras de la misma moneda. No hay personas responsables porque no se han formado caracteres morales que se sientan obligados a dar cuenta y hacerse cargo de lo que hacen y de lo que ocurre en su mundo. Dicho de otra forma, y haciendo uso de la figura evangélica, la ley por sí sola no fomenta la figura del «buen samaritano» ${ }^{4}$ que acude en ayuda del que sufre. ¿Cómo mantener, en tales condiciones, lo que para Rawls debiera ser un bien básico: las bases sociales de la autoestima?

2) La segunda objeción que se me ocurre es que los conflictos cotidianos nunca son conflictos entre derechos abstractos, sino más bien entre distintas concepciones del bien. Este punto se pone de manifiesto con claridad en las cuestiones que está planteando la bioética: ¿hay que dar vía libre a la reproducción artificial, a la investigación con embriones, a la información genética? Responder con una ley - es decir, con una prohibición - no es otra cosa que imponer una determinada concepción de la vida buena sobre las demás, y plantearse en abstracto si el embrión y el feto merecen la misma consideración que la persona. Es lo que está ocurriendo con la discusión sobre la legitimidad de investigar con embriones. Ante la discrepancia de puntos de vista, se ha impuesto el punto de vista gubernamental: se prohíbe investigar porque se acepta que el embrión vale igual que un ser humano nacido y vivo. Preguntas como: qué respeto merece el embrión, si es bueno para la sociedad que la reproducción artificial se vea como una forma alternativa de reproducción y no como una terapia, si la publicidad de los datos genéticos debe ser entendida como una expresión de solidaridad, no son dirimibles sólo jurídicamente. En el trasfondo de todos ellos hay distintas concepciones de lo que es bueno para nosotros.

Precisamente porque las concepciones del bien son plurales, el Estado coherentemente liberal renuncia a imponer una concepción del bien sobre otra y afirma su neutralidad total ante las distintas preferencias de la gente. El problema, sin embargo, es que esa neutralidad puede acabar menoscabando el ideal de justicia y los bienes considerados básicos. Vuelvo a los ejemplos de la bioética, que son los más claros: si creemos, por ejemplo, que en caso de incapacidad del paciente le corresponde a la familia decidir por él, ¿no estaremos dando un valor a la familia más que discutible desde una perspectiva cultural distinta a la nuestra? Si atendemos a las demandas de ciertas mujeres musulmanas, que se niegan a ser atendidas por ginecólogos varones, ¿estamos simplemente condescendiendo a otra forma de vivir tan válida como la que se desprende de nuestras costumbres? Es fácil que esta tolerancia acabe dejando a la justicia sin contenido sólo por miedo a llenarla de contenidos antiliberales. ¿Qué concluir? ¿Debería intervenir más el Estado? ¿Habría que regular más? ¿O más bien el ciudadano debería tener en

${ }^{4}$ Cf. El libro de Helena Béjar, El mal samaritano, Barcelona, Anagrama, 2001. 
cuenta su compromiso con la sociedad al elegir su bien, ya que los bienes más generalizables serán los que acabarán siendo parte del contenido de la justicia?

Tenemos, por una parte, la convicción de que los bienes, o las opciones de felicidad, tienen que ser particulares. Por otra, una concepción de la moral y de la ciudadanía basada en la reivindicación de unos derechos o de unos principios de la justicia. Cuando los derechos o la idea de una justicia universal choca con ideas particulares del bien, parece que no hay sino dos opciones: o consideramos que todas las concepciones del bien son igualmente válidas y justas, o tendemos a imponer una de ellas sobre las demás, considerándola la encarnación de la justicia. Es lo que está ocurriendo con las identidades culturales que brotan por todas partes: o las consideramos a todas derechos colectivos, o las negamos para afirmar una identidad cultural a costa de las otras. No hay una vía media, que consistiría en aceptar que los derechos son interpretables y lo son precisamente a la luz de los bienes particulares. El derecho a la libertad, pongo por caso, es distinto en Europa, con un Estado de bienestar consolidado, y en Estados Unidos, donde la solidaridad con el desfavorecido no es un deber jurídico impuesto por el Estado de bienestar. El debate sobre la eutanasia se desvirtúa si se plantea como el derecho o el no derecho a elegir el momento de la propia muerte. Cuando alguien pide que le ayuden a morir dignamente no está reivindicando sólo un derecho, sino pidiéndole a la sociedad que comparta su punto de vista sobre el bien. Nos cuesta tomar decisiones en solitario, queremos que los demás nos acompañen en las decisiones, por eso pretendemos socializar nuestras visiones de la vida buena.

En realidad, el abuso del lenguaje de los derechos - como el abuso de la idea de contrato como forma de todas las relaciones humanas - está supliendo la ausencia de solidaridad, la falta de una interrelación más fluida y constante entre los individuos. La protección de los animales o de la naturaleza se plantea en términos de derechos. Pero ¿no es absurdo hablar de los derechos de los cerdos o de los árboles cuando es un hecho que la interdependencia de la vida planetaria se está degradando? Seguramente es también la falta de socialidad la culpable de trasladar el lenguaje de los derechos a los grupos, una forma insatisfactoria de reconocer que los seres humanos son sociales a la vez que autónomos: «No necesitamos una nueva carpeta de derechos colectivos, sino un concepto pleno de personalidad humana y una forma más ecológica de pensar en la política social» ${ }^{5}$.

En conclusión: 1) las distintas concepciones del bien son las que van nutriendo el ideal de justicia, no al revés, y no sólo lo alimentan, sino que ayudan a entenderlo e interpretarlo; 2) en consecuencia, las distintas concepciones del bien no pueden ser consideradas como asuntos exclusivamente

5 Mary Ann Glendon, op. cit., p. 137. 
privados y particulares. La responsabilidad ante las opciones de vida buena o de felicidad se correspondería con el sentido moral o con una construcción abierta e inacabada del bien común.

\section{c) El lugar de la moral en las democracias liberales}

Una democracia liberal no es algo dado: hay condiciones que la favorecen y condiciones que la amenazan. El carácter de las personas es importante: es importante que los ciudadanos actúen como tales y que los políticos actúen como servidores públicos. Cuando las estructuras tradicionales se desmoronan, como ha explicado Anthony Giddens ${ }^{6}$, nos preguntamos dónde se adquiere la capacidad de preocuparse por el bien común y crear una moralidad colectiva. Por eso no sólo vemos cómo se extiende la demanda de moral o de ética, sino que también parece imprescindible educar en valores.

Tocqueville y Durkheim, ambos preocupados por el mantenimiento de esa moralidad colectiva, se refirieron a la necesidad de mantener las «instituciones locales», los «grupos secundarios», como espacios de socialización y moralización de la persona. Pensadores actuales (como la misma Glendon) proponen repensar el papel indiscutible de la familia que, sin embargo, ya no tiene la estructura tradicional, sino muchas estructuras distintas. Por mi parte, me he referido a la necesidad de una «moralidad organizada» o de «institucionalizar la moral» para promover una actividad autorreguladora y responsable ${ }^{7}$. Ya no podemos defender que el hombre sea sólo o esencialmente un animal político, pero sí cabe reconocer su realidad y, sobre todo, los deberes contraídos con respecto a la sociedad, sin perjuicio de salvaguardar su autonomía. Si no conseguimos mantener una tensión creativa entre las tres fuerzas - Estado, mercado y sociedad civil-, en el mejor de los casos, el Estado asumirá la función de preservar las esencias constitucionales y el individuo irá descubriendo que su bien particular se mueve al vaivén de los intereses del mercado.

Nos falta un discurso público concerniente a la responsabilidad, la socialidad y la sociedad civil, lo cual deja en nuestras manos el pensar qué clase de personas queremos ser y qué tipo de sociedad queremos construir. «Nuestra pretenciosa retórica de los derechos y nuestra concepción del sujeto de derechos como un individuo autónomo nos alejan de pensar qué tenemos en común para fijarnos en lo que nos separa. Nos alejan de la participación en la vida pública y fomentan la maximización de las satisfacciones privadas» ${ }^{8}$. No se trata de consensuar valores para tener un subsuelo

${ }^{6}$ Anthony Giddens, Modernity and Self Identity, Polity Press, 1991.

7 Victoria Camps, Una vida de calidad, Barcelona, Ares y Mares, 2001.

${ }_{8}$ Mary Ann Glendon, op. cit., p. 143. 
común, pero sí de deliberar y discutir sobre los distintos valores y concepciones de la vida buena. ¿Para qué? Para ir descubriendo la ley moral que querríamos universalizable, para no estancarnos moralmente y entender mejor los principios fundamentales. Así se llegó a la abolición de la esclavitud en Estados Unidos, al reconocimiento del sufragio femenino, a la consideración del valor de la educación o de la protección de la salud como bienes básicos.

El individuo kantiano poseedor de la ley moral, capaz de acceder a la moral universal desde su individualidad, el sueño ilustrado del uso público de la razón desde la individualidad, es pura ficción. La moralidad, lo que da contenido al ideal de justicia y nutre la acción política, es el resultado de una construcción colectiva. La única forma de mantener viva la moral como motor de cambio y de aplicación de los principios de la justicia es llevando la moral al terreno del ethos, de la formación del carácter, de las virtudes. Hacen falta organizaciones sociales que creen clima de moralidad, pero también personalidades morales.

El comunitarismo y el republicanismo insisten en este punto, pero no siempre lo hacen bien. No es fácil determinar cuáles deben ser las «virtudes liberales». La prioridad de la libertad tiende a reducir los valores políticos liberales a la tolerancia y el respeto de los derechos ajenos. Hasta el punto de que es difícil que los regímenes liberales rechacen grupos de no liberales (nazis, terroristas). Con esta dinámica ponemos en peligro a la democracia y al Estado de Derecho. Desde un relativismo cultural o moral sin límites acaban siendo cuestionados los derechos más fundamentales, incluso como derechos abstractos.

A mayor libertad, mayores posibilidades de elección pero también mayor riesgo, incertidumbre y miedo. Una sociedad incierta no puede estar formada por individuos atomizados que, espontáneamente y sin la coacción del Estado, sólo llegarán a acuerdos interesados. ¿Qué debe unir a los miembros de una sociedad liberal? ¿No debe haber para el liberalismo formas de realizarse humanamente? La separación entre hechos y valores, la convicción de que la razón no puede descubrir lo que es bueno para el hombre, también la idea de que los bienes privados son inconmensurables, ¿han de acabar en la conclusión escéptica de que no cabe distinguir un bien o un mal racional?

El ser humano es libre de escoger sus ideales, pero no de contemplar las distintas preferencias como si todas ellas tuvieran el mismo valor. Ahí radica la diferencia entre la autarquía y la autonomía, que es capacidad crítica y de formación del carácter. Nuestra autonomía no es la kantiana, que elige desde la razón pura, sino una «autonomía situada», que elige entre distintos criterios o ideales, como forma de ser dentro de una comunidad. Dicho de otra forma, nuestra identidad humana se forma sobre la base de un «lenguaje moral público», con significados públicos y razones igualmente públicas en 
las que se apoyan dichos significados. Sólo a través del lenguaje podemos expresar la propia individualidad. Sólo a través de razones públicas podemos defender lo propio, como nos enseñó Wittgenstein. El desacuerdo sobre la vida buena, el pluralismo, no deberían ser una condición y estímulo para vivir cada cual a su aire y sin preocuparse de los demás, sino más bien un motivo para reflexionar sobre los valores compartibles. La conciencia de sí, el autodominio, la voluntad de compromiso, la apertura al cambio y el apoyo crítico a la moral pública de la justicia liberal deberían constituir el meollo de las virtudes liberales. Contra un exceso de virtudes «judiciales», «legislativas» $\mathrm{y}$ «ejecutivas», virtudes que fomentan la indiferencia frente a los demás, la tolerancia sin discriminación, y el interés individual, conviene promover «virtudes liberales» ${ }^{\text {. }}$.

Decía Aristóteles que «debemos hablar sobre el bien y sobre qué es bueno, no en sí sino para nosotros» ${ }^{10}$. Dicho bien - explica Martha Nussbaum - es frágil, vulnerable, antropocéntrico, no contrastable con una idea o medida suprahumana, eterna y platónica de lo que es bueno. La ética, en consecuencia, nos proporciona un conocimiento del bien que no es episteme, sino poco riguroso, esquemático. Los bienes son inconmensurables: el valor, la justicia, la amistad, la generosidad, son valores diferentes que no pueden intercambiarse y que muchas veces entran en contradicción entre ellos.

Desde esta perspectiva, los principios y reglas universales, los ideales de justicia, han de ser vistos como directrices o normas derivados de la práctica, síntesis de decisiones particulares, de buenos juicios hechos por personas singulares. No al revés. Lo particular no vale en la medida en que es reflejo de la regla o del principio universal (como dirían Kant o Rawls), sino más bien la regla ha acabado valiendo al generalizarse lo que empezó siendo particular. Por eso es en la decisión del phrónimos donde se muestra la ética: la ley es considerada como la síntesis de las decisiones prudentes.

«La intelección práctica se parece a la percepción en que no es inferencial ni deductiva; es esencialmente la capacidad de darse cuenta, reconocer, seleccionar y responder a determinados atributos importantes de una situación compleja» ${ }^{11}$. Esta capacidad de discernimiento - de conscientia- es lo que hace falta para aplicar bien la ley, para criticarla y cambiarla. El lugar de la moral está no sólo en los principios, sino en el carácter de las personas. Como decía Aranguren, la moral es el fundamento de la democracia: «moral en tanto que compromiso sin reserva, responsabilización plena. Y moral en tanto que instancia crítica permanente, actitud crítica siempre vigilante» ${ }^{12}$.

${ }^{9}$ Cf. Stephen Macedo, Liberal Virtues, Oxford, Clarendon Press, 1991, cap. 7.

10 Magna Moralia, 1182b, pp. 3-5.

${ }_{11}$ Martha Nussbaum, La fragilidad del bien, Visor, Madrid, 1995, p. 389.

12 José Luis Aranguren, «La democracia como moral», Obras completas, vol. 5. 


\section{LA MOTIVACIÓN MORAL}

Hemos visto que, en el siglo $\mathrm{xx}$, cualquier teoría moral parte del supuesto de que las concepciones del bien son plurales y que es bueno que así sea y que se discuta sobre la base de la pluralidad porque eso es lo que mantiene viva a la comunidad moral. La pregunta que planteo ahora acepta tal supuesto y quiere ir más allá: ¿cómo conseguir comunidades moralmente animadas? En términos aristotélicos, ¿cómo no hablar sólo de la virtud sino hacer hombres virtuosos y buenos? O en términos kantianos: ¿por qué hay que ser moral? ¿Cómo combatir el escepticismo, el nihilismo?

El problema es tan antiguo como la filosofía moral. Se remonta a las discusiones sofístico-platónicas sobre la cuestión de si la moral es natural o antinatural. El mito de Giges, al comienzo de La República, es presentado por Glaucón como la prueba de que somos justos sólo por obligación y temor a la ley, al castigo o a la reprobación social, pero no por una tendencia natural a serlo. De hecho - afirmará el sofista - todos preferimos cometer una injusticia a padecerla. De un modo parecido, aunque más moderado, Aristóteles, pese a reconocer que la vida virtuosa está potencialmente en la naturaleza de cada hombre, tras haber descrito el cómputo de virtudes, acaba la Ética a Nicómaco proclamando la necesidad de la ley para que la ética llegue a cumplirse: hay que transitar de la ética a la política para que la virtud se haga práctica, pues la retórica, por buena y bienintencionada que sea, es insuficiente para hacer a los hombres buenos, y «la pasión parece ceder no al argumento sino a la fuerza». Así, necesitamos leyes, pues «la mayor parte de los hombres obedece más a la necesidad que a la razón, y a los castigos más que a la bondad» ${ }^{13}$.

Kant, por su parte, concluirá la Fundamentación de la metafísica de las costumbres sin hallar respuesta a la pregunta: ¿cómo es posible que la ley moral obligue? Pues si bien el imperativo categórico es vinculante, la ley moral por sí sola no nos vincula. Para que lo haga, hace falta que nos situemos en el reino de los fines y nos veamos como miembros de ese lejano reino. Como habitantes del mundo empírico, donde el deseo traiciona a la razón, no tenemos mucho que hacer en lo que a la moral se refiere ${ }^{14}$.

\footnotetext{
13 Aristóteles, Ética a Nicómaco, 1179b-1180a.

14 «Hay ciertas disposiciones morales que, si no se poseen, tampoco puede haber un deber de adquirirlas. Son el sentimiento moral, la conciencia moral, el amor al prójimo y el respeto por sí mismo (la autoestima): tenerlas no es obligatorio, porque están a la base como condiciones subjetivas de la receptividad para el concepto del deber, no como condiciones objetivas de la moralidad. En su totalidad son predisposiciones de ánimo, estéticas pero naturales (praedispositio), a ser afectados por los conceptos del deber; no puede considerarse como deber tener estas disposiciones, sino que todo hombre las tiene y puede ser obligado gracias a ellas. La conciencia de ellas no es de origen empírico, sino que sólo puede resultar de la conciencia de una ley moral, como efecto de la misma sobre el ánimo» (Kant, Metafísica de las costumbres, párr. 399).
} 
Otros filósofos, más integradores de la razón y el sentimiento que el propio Kant, han luchado contra esa escisión del ser humano que separa a la intelección racional de la pasión, tachándola de especulación teórica sin base real. Spinoza, por ejemplo, se niega a pensar que el bien y el mal sean algo extraño a los afectos humanos y analizable al margen de ellos: «No deseamos las cosas porque son buenas, sino que son buenas porque las deseamos», afirma haciéndose eco de la más pura tradición estoica. Hume, por su parte, el filósofo del sentimiento por antonomasia, compara al filósofo teórico con un «anatomista» que estudia la naturaleza humana como un tema de especulación abstracta, «fría y poco atractiva», si bien imprescindible para la filosofía práctica. El filósofo práctico, en cambio, es como un «pintor» que sabe que la virtud es un objeto valioso y «la pinta con los colores más agradables, valiéndose de la poesía y de la elocuencia, desarrollando su tema de una manera sencilla y clara, lo más indicada para agradar a la imaginación y movilizar nuestros sentimientos» ${ }^{15}$.

En realidad, ambos puntos de vista no son tan distintos. En uno y otro caso se da por supuesto que ser moral implica un esfuerzo, la adquisición de algo que no se tiene y por lo que hay que luchar. La diferencia estaría sólo en el método o los medios para lograrlo. Si Kant pretende que sea la mera contemplación de la ley moral la que nos mueva a respetarla y a cumplirla, Hume (o Spinoza) no le hacen ascos al disfraz de la ley, incluso a un cierto engaño que nos la presente más atractiva y cercana a los afectos. Si es cierto que los hechos y los valores están separados por un abismo infranqueable desde la racionalidad pura, algo habrá que hacer para formar el carácter, producir un sentido común de la moralidad, que contribuya a formar el sentimiento y a formar la conciencia. Nos guste o no, nuestro lenguaje está lleno de conceptos valorativos. Cómo hacer que no pierdan su fuerza moral, sino que la transmitan, que no se degraden en vocablos vacíos más proclives al rechazo que a la adhesión.

La distancia lingüística y real entre el ser y el deber ser es lo que nos hace pensar que no existen razones suficientes o convincentes para el bien o la justicia. Aunque la nuestra sea una «estructura moral», porque no tenemos más remedio que elegir nuestra vida (homo is quammodo omnia), esa estructura no impide caer en la «desmoralización» con demasiada frecuencia, en la falta de fuerza moral. En las sociedades plurales y heterogéneas, donde las razones y motivos para la acción son de tipo muy diverso, donde la secularización del pensamiento nos priva del amparo de una doctrina o de una ideología que nos dé directrices y motivos para actuar, es fácil la desmoralización o la anomia moral. ¿Para qué ser buenas personas, si no es la buena conducta la que puede garantizarnos la felicidad?

El escéptico moral es el que se niega a ser persuadido por razones o argu-

${ }^{15}$ Hume, Investigación sobre el entendimiento humano, sec. I. 
mentos morales, negación derivada del supuesto de que los problemas normativos son irresolubles y carecen de respuesta. Y aun cuando hubiere respuestas, éstas quedarían demasiado lejos de los intereses inmediatos, que son lo que realmente nos afecta y nos importa. Es más difícil combatir el escepticismo moral que el epistemológico, pues en aquel caso no se trata de persuadir de que ciertos argumentos son verdaderos, sino de que su validez obliga a actuar de acuerdo con ellos.

La pregunta planteada al principio de esta sección se convierte, así, en esta otra: ¿por qué carecen de fuerza los argumentos morales?, ¿porque exigen demasiado del ser humano?, ¿porque éste es incapaz de ver su utilidad?, ¿porque su validez no es demostrable? El intento de encauzar estas preguntas se desdobla en los dos argumentos siguientes.

\section{a) El argumento egoísta}

Dice dicho argumento que los fines morales nunca coincidirán con nuestros deseos, que la razón y la pasión no llegarán a unirse nunca, que es imposible ser altruista. El argumento deriva de la concepción del ser humano como radicalmente egoísta.

Thomas Nagel, en The Possibility of Altruism, se propuso refutar dicha tesis a partir de un concienzudo y lúcido análisis de la naturaleza del altruismo. Su hipótesis de partida es que constituye un error pensar que ser altruista significa sólo sacrificarse y renunciar a hacer lo que uno quisiera. Es una convicción derivada de esta otra: que nunca hay razones objetivas ni obvias para promover los intereses de los demás, que uno sólo encuentra razones para actuar en interés propio. ¿Por qué han de motivarnos los intereses ajenos? La imposibilidad de pensar seriamente el altruismo deriva de la concepción hobbesiana de la persona, de donde a su vez nacen las modernas teorías del contrato social. Concepciones para las que es imposible explicar la moralidad desde la racionalidad individual entendida como mera racionalidad instrumental. El ser racional, de acuerdo con tales teorías, jamás llegará a reconciliarse con la sociedad o con algún tipo de bien común. Por eso hace falta el contrato, un contrato movido precisamente por el interés individual, egoísta, el cual logrará no tanto la moralización de la persona como la sumisión de ésta a los motivos o razones morales.

Nagel ve en dichos argumentos una identificación errónea entre motivación para hacer algo y deseo de hacerlo. Ningún fumador desea dejar de fumar ni ningún alcohólico desea dejar la bebida, lo que no significa que, en ambos casos, no tengan razones y motivos para abandonar las respectivas adicciones. Nadie desea renunciar a las comodidades de que disfruta para preocuparse por los demás, por los que sufren y viven mal, pero que no exista deseo no significa que no existan razones. Reconocer la realidad del otro 
como un igual, plantearse la pregunta clásica y canónica: ¿cómo te gustaría que te trataran si estuvieras en el lugar del otro?, es tan intrínseco a la naturaleza humana - sostiene Nagel y pienso que no se equivoca - que no puede considerarse una razón subjetiva sino objetiva para actuar moralmente.

\section{b) El argumento relativista o de la pluralidad de razones}

Según tal argumento, en las sociedades plurales y heterogéneas, sin doctrinas comprehensivas unificadoras, no hay razones objetivas ni válidas para todos que obliguen a actuar moralmente.

Sería la tesis que Isaiah Berlin desgrana a lo largo de muchos de sus escritos, y que resume en la teoría de que los filósofos, en general, se han equivocado al defender casi unánimemente estas tres cosas: 1) que todos los hombres tienen un fin verdadero: dirigirse a sí mismos racionalmente; 2) que los fines de todos los seres racionales tienen que encajar en una sola ley universal y armónica que unos hombres pueden ser capaces de discernir más que otros; 3 ) que todos los conflictos se deben solamente al choque de la razón con la sinrazón ${ }^{16}$.

Lo que dice Berlin es cierto: nadie está en posesión de la razón absoluta, por lo que será difícil encontrar razones universales que avalen y fundamenten lo que no son sino opciones particulares o grupales, pero no verdades universales. De donde, sin embargo, no se infiere que no seamos capaces de construir razones públicas. Si somos inevitablemente morales, quiere decir que nuestra identidad humana es normativa, y las normas, por definición, tienen que ser comunes, objetivas y públicas. Tiene que haber, pues, razones públicas (o un lenguaje público, como ya veíamos en el apartado anterior) a favor del comportamiento moral. Lo vio muy bien Wittgenstein: para entendernos, no sólo hace falta «una concordancia en las definiciones, sino también (por extraño que parezca) una concordancia en los juicios» ${ }^{17}$. Los juicios nacen del intercambio recíproco. Como explicaba Moore, es incoherente decir que algo es bueno sólo para mí, pues nadie lo entendería. El lenguaje privado no puede existir. Tampoco las razones son privadas.

A través del lenguaje se forja la identidad humana. En un bonito texto titulado Las fuentes de la normatividad, Christine Korsgaard advierte de la necesidad de construir «identidades prácticas» que medien entre el concepto de bien o de justicia y la concepción de lo que yo soy y debo hacer para ser buena y justa. No puedo saber lo que debo hacer si no sé quién soy, si no sé de qué forma perderé mi identidad y mi integridad, seré despreciada o reprobada por los demás. Las nociones de pecado o de honor, en otros tiempos,

${ }_{16}$ Véase, por ejemplo, Cuatro ensayos sobre la libertad, prólogo, Madrid, Alianza Editorial.

17 Wittgenstein, Investigaciones Filosóficas, p. 242, y también: «El estado civil de la contradicción, o su estado en el mundo civil: ése es el problema filosófico», ibid., 125. 
dejaban clara esa identidad. Que hoy carezcamos de tales nociones y no podamos predeterminar lo que lleva a perder la identidad moral no significa que esa identidad no sea igualmente necesaria. «La concepción de la incorrección moral, tal como ahora la comprendemos, corresponde al mundo en el que nosotros vivimos, aquel al que la Ilustración dio lugar, donde la identidad de una persona es su relación con la humanidad misma» ${ }^{18}$. Esa identidad práctica se produce en las relaciones personales, en la reciprocidad de unos con otros, en la vida común, no es la identidad consigo mismo de un individuo abstracto. Uno es miembro del partido de la humanidad y también de comunidades pequeñas y locales: las obligaciones hacia individuos concretos se generalizan, a fin de cuentas, en obligaciones hacia la humanidad.

Lo contrario de esa identidad humana - sigue diciendo la filósofa citada- «en proceso de formación» son las «identidades ficticias» tan queridas por los filósofos idealistas. Es la identidad del ciudadano legislador del reino de los fines de Kant. O la del ciudadano liberal puro que pretende mediar entre el concepto de justicia y el principio de la distribución de los bienes básicos. Korsgaard, por el contrario, entiende la construcción de la identidad como una necesidad mucho más material, de la que tomamos conciencia precisamente cuando está en peligro: «Un ser humano es un animal cuya naturaleza consiste en construir una identidad práctica que sea normativa para él. Es una ley para sí mismo. Cuando alguna manera de actuar representa una amenaza a su identidad práctica y la reflexión le revela este hecho, la persona descubre que debe rechazar esa manera de actuar y actuar de otro modo» ${ }^{19}$. Ese rechazo es como el dolor, pero con una diferencia: el dolor es un rechazo irreflexivo a algo que nos amenaza, en tanto la obligación de mantener la identidad que peligra con desvanecerse es un rechazo reflexivo: no debo hacer esto porque me comportaré inhumanamente, perderé mi integridad.

Ser capaz de sentir dolor por la humanidad sería, pues, la condición de la moralización, del mantenimiento de la moral como un vivir moralizado o «tener moral». El escepticismo moral, en cambio, equivaldría a negar el valor de lo humano, a la insensibilidad hacia la falta de humanidad. Una humanidad que, al decir de Montaigne, no hay que descubrir en ninguna parte porque la llevamos dentro, está en cada uno de nosotros: «Cada hombre lleva en sí la forma de toda la humanidad.»

No obstante, el problema de las identidades del que tanto nos gusta hablar no consiste sólo en la dificultad de construirlas dada la pérdida de puntos de referencia inmutables, sino en el hecho de que las identidades prácticas que hoy funcionan no son precisamente las morales. Son identidades simplificadoras: las que brinda el nacionalismo, la religión, las profesiones, los perfiles creados por la sociedad de consumo. Se ha dicho que el hombre actual es un «hombre modular», hecho a base de módulos, sin esen-

${ }^{18}$ Christine Korsgaard, Las fuentes de la normatividad, México, UNAM, 2000, p. 149.

19 Ibid., p. 
cia, donde cada actividad va por su cuenta, sin el respaldo del resto ${ }^{20}$. De acuerdo con tal estructura, no es la identidad humana lo que se persigue, sino eso que Berlin llamó «la búsqueda del estatus»: el deseo de reconocimiento social. En ese anhelo de estatus, el individuo anhela sentirse parte de un grupo y es en calidad de tal que pide reconocimiento. Con lo cual la identidad moral se reduce a otra cosa: a una identidad profesional, patriótica, religiosa, de género. Quienes se plantean así las identidades «están dispuestos a cambiar el penoso privilegio de decidir - "el peso de la libertad" - por la paz, la comodidad, la relativa innecesariedad de tener que pensar que lleva consigo una estructura autoritaria o totalitaria» ${ }^{21}$.

Dicha búsqueda de reconocimiento es la que alienta a las propuestas comunitaristas. Algunas - como la de Taylor- responden al anhelo de hacerse con una identidad moral universal, propia de la humanidad como tal. Otras, por el contrario, piensan que ya no es posible rebasar la identidad comunitaria si queremos dar respuesta a la pregunta: ¿quiénes somos? El ejemplo indiscutible es MacIntyre. Pero, más allá de las propuestas filosóficas, lo que es evidente es que el objetivo de forjarse un carácter moral, ser una buena persona, no cuenta de hecho como el propósito último de la vida humana, no es ese fin al que, según Aristóteles, hay que tender. Tampoco parece que sea el fin de la educación de nuestro tiempo el hacer buenas personas, sino más bien personas formadas, instruidas, capaces de desenvolverse con éxito en la vida y de integrarse en la sociedad.

Ronald Dworkin, al referirse a ciertos problemas de la vida humana, como el del aborto o la eutanasia, hace una distinción que puede sernos útil. Distingue entre los «intereses de experiencia» y los «intereses críticos». Aquéllos son intereses inmediatos, el interés por algo que reporta una gratificación o un placer contrastable. Los «intereses críticos», por el contrario, remiten al sentido de la vida, a la calidad de la misma. No preguntan: ¿qué busco en este instante?, sino ¿qué busco en la vida en general, qué quisiera conseguir? Y sigue Dworkin: aunque no coincidamos en los intereses críticos, y aunque no lleguemos a poder verbalizarlos, éstos son los que realmente importan porque son los que dan fundamento a las opciones morales. Cuando las opiniones de las personas - sobre la muerte, por ejemplo- son diversas, la función del Estado o del Derecho no es intervenir e imponer una concepción entre otras, pero sí «estimular al individuo a adoptar decisiones con respecto al propio futuro de la mejor forma posible» ${ }^{22}$. Al ciudadano debe interesarle la salud moral de la comunidad tanto como la justicia: «Las comunidades políticas poseen una vida común cuyo éxito o fracaso forman parte de lo que hace que la vida de sus miembros sea buena o mala» ${ }^{23}$.

${ }^{20}$ Ernest Gellner, Conditions of Liberty: Civil Society and its Rivals, Londres, Penguin, 1996, pp. 98-100.

${ }^{21}$ Isaiah Berlin, El fuste torcido de la humanidad, Barcelona, Península, 1992, cap. I.

22 Ronald Dworkin, El dominio de la vida, Barcelona, Ariel, 1994, pp. 262 ss.

${ }^{23}$ Ronald Dworkin, «Liberal Community», California Law Review, vol. 77, núm. 3, pp. 479-509. 
El discurso recién iniciado sobre la formación de identidades morales me ha remitido a Dworkin y, en general, me lleva a la ética aplicada. Pues dicha forma de entender la ética ha aparecido como consecuencia de la necesidad de hacer explícita la dimensión ética que deben tener las profesiones y la vida pública. Hay un modo de acercarse a la ética aplicada muy simple: hagámonos con un código ético y apliquémoslo, así regeneraremos nuestras prácticas. Se trata de una percepción pobre de lo que debería ser la ética. Una percepción que le da la razón a Alain Etchegoyen cuando se lamenta de que la Moral se haya disuelto en múltiples éticas corporativistas, localistas, interesadas, profesionales ${ }^{24}$. La ética aplicada se ofrecería, en tal caso, como un método, o una serie de ellos, para resolver problemas prácticos. Una nueva forma de regular la práctica cercana a la legislación. No me parece la visión correcta. No se trata de agarrar unos principios éticos para llevarlos a la medicina, a la empresa o a la televisión, sino de concebir las prácticas - eso que Aristóteles llamó praxis - desde una dimensión más rica y más compleja que la que les dan los fines meramente instrumentales.

Concretamente, veo la ética aplicada como la ocasión de repensar la autonomía de la persona en el seno de la colectividad. La autonomía como autorregulación. Una práctica dirigida a ir construyendo la identidad moral que necesitamos, entendida como el proceso de repensar las conductas en función de ciertos valores que no deberían perderse, o de enriquecimiento con concepciones del bien que contrastan con las nuestras. Construir una identidad moral no es resolver problemas morales. Es más bien acertar a plantearlos y no dejar de verlos como problemas. Lo único bueno sin restricción - dejó dicho Kant - es la voluntad buena, que es la voluntad de hacer el bien, no la de decir en qué consiste el bien, un saber que nadie tiene en exclusiva. Es en la voluntad donde yace el éxito o el fracaso de la ética, aunque también sea cierto que la buena voluntad sola acaba siendo decepcionante. No obstante, construir una identidad moral no puede ser sino el empeño por mantener la voluntad de cambiar las cosas y mejorarlas. Sobre todo mantener una tensión entre la falta de voluntad y la voluntad misma. Por eso carece de interés la pregunta habitual sobre si esta o aquella opción es más o menos ética que esta otra. Nada es perfecto en este mundo. Muy pocas opciones son moralmente impecables y muy pocas totalmente inmorales (aunque hay algunas que ejemplifican claramente el mal). La diferencia entre la moralidad y la falta de moral está entre quienes mantienen la aspiración y la esperanza en ser algo mejores de lo que son y quienes han borrado esa aspiración de sus vidas porque piensan que carece de sentido o que es inútil. Como ha escrito Javier Muguerza, la ética siempre estará más lejos, la sociedad nunca será demasiado justa, pues la justicia, «al igual que la línea del horizonte, se aleja de nosotros a medida que avanzamos hacia ella.

${ }^{24}$ Alain Etchegoyen, La valse des éthiques, París, Éditions François Bourin, 1991. 
Dicho de otra forma, la justicia no es cosa de la democracia como institución o establecida, sino de esa aspiración perpetuamente insatisfecha que era la arangureniana democracia como moral» ${ }^{25}$.

A diferencia de la moral religiosa que conoce el fin de la historia, la moral laica más bien descree de la realización moral. Nuestra tarea es más modesta: tenemos que contentarnos con que la sola voluntad de humanizar el mundo baste para dar sentido a la existencia humana. No es la «obstinada adversidad» ni el «agotamiento de una lucha desigual» - dice Camus - lo que nos sume en la desesperanza, sino la falta de «razones para luchar», o incluso el que «no sepamos si hay que luchar». El secreto para mantener esas razones quizá consista en no creernos dioses o seres imbuidos del poder de salvar al mundo. Lo dice mejor el mismo Camus: «Estoy convencido de que ya no podemos tener la esperanza razonable de salvarlo todo, pero, al menos, podemos proponernos salvar vidas para que el futuro siga siendo posible» ${ }^{26}$.

\section{LA ÉTICA FRENTE A LOS FANATISMOS}

Las dificultades para adquirir una personalidad moral, en una época heterogénea y pluralista como la nuestra, no sólo tienen sus raíces en las cuestiones analizadas hasta ahora, como la diversidad de referencias, la desorientación ante ellas y la mayor visibilidad y atractivo de los valores no éticos. Además de todos estos elementos, se constata cada día - y mucho más desde el 11 de septiembre - una presencia creciente de los fanatismos de carácter religioso, político o étnico. Tal vez el fenómeno del fanatismo o el fundamentalismo no sea sino la consecuencia de la pluralidad de puntos de vista y el desconcierto que el mismo pluralismo provoca, lo que puede dar origen tanto a actitudes indiferentes como al rechazo a vivir en la incertidumbre moral. No pretendo, sin embargo, dar aquí una explicación del fanatismo o de sus causas, que siempre acabaría siendo reduccionista y poco creíble. Sólo pretendo hacer ver el peligro que tal fenómeno representa precisamente ante la dificultad de construir identidades morales. El fanático cuenta con el respaldo de doctrinas que le dicen quién es y qué debe hacer. No necesita forjarse una identidad porque ya la tiene, y mucho menos necesita justificarla porque la doctrina en la que cree lo hace por él.

Dicho brevemente, y recogiendo ideas ya desarrolladas en los apartados anteriores, el fanático es inmoral, pero no le falta entusiasmo moral. Tiene ideas claras, sabe qué debe hacer, y puesto que carece de dudas al respecto no vacila tampoco en utilizar medios inmorales para sus fines. Cuando el

25 Javier Muguerza, «Derechos humanos y ética pública», en Ética pública y Estado de Derecho, Madrid, Cuadernos de la Fundación Juan March, p. 87.

${ }_{26}$ Albert Camus, Moral y política, Buenos Aires, Losada, 1978, p. 104. 
fanático mata por sus ideas, no ve la muerte, sino unos ideales o unas directrices. Es incapaz de darse cuenta de lo que expresó maravillosamente Castillión en su polémica con Calvino: «Matar a un hombre por sus ideas no es defender una doctrina, es matar a un hombre.» Para el terrorista, el hombre que convierte en su diana queda oculto tras lo que ese hombre representa para él, que es contra lo que está luchando. Desprecia a la humanidad concreta porque la reduce a unos símbolos. La incapacidad de distinguir lo que merece la pena conservar por encima de todo, lo que no puede utilizarse nunca como un medio, es lo que lo hace inmoral, pero no amoral o indiferente a la moral. Por lo mismo, el fanático no vive desmoralizado ni carece de esa fuerza moral que estábamos echando de menos en nuestro mundo. Su moral es de grandes convicciones, no de convicciones débiles. Una moral de principios absolutos y, como tales, indiscutibles. Una ética de principios en el peor sentido de la expresión. El que rechaza Max Weber cuando advierte de que el hombre de principios «desconoce todos los defectos del hombre medio»y, por lo tanto, todas las limitaciones de este mundo.

Otro aspecto del comportamiento fanático es el totalitarismo que acompaña a todos los fundamentalismos. Bobbio se ha referido a la pervivencia de un componente jacobino en los movimientos modernos. La creencia en la primacía y en la potencialidad de la política para transformar la sociedad - explica - ha derivado en totalitarismos que han estado presentes en los movimientos socialistas, nacionalistas y fascistas del siglo $\mathrm{XX}^{27}$. La contradicción entre este espíritu jacobino y el compromiso con el pluralismo, la impaciencia ante las reglas democráticas que suelen ser lentas y poco eficaces para conseguir objetivos claros, ha dado bazas a las respuestas fundamentalistas.

Creo que el análisis ético más convincente que se ha hecho del fanatismo, desde el punto de vista de la ética, es el que hizo, hace años, Richard M. Hare ${ }^{28}$ en un célebre artículo titulado «Fanaticism and Amoralism». La tesis de Hare allí defendida es que «las raíces del fanatismo radican en el intuicionismo y en el rechazo o la incapacidad de pensar críticamente». Más en lo segundo que en lo primero. Es posible que el fanático tenga principios equivocados, incluso malos, pero ésta no suele ser la fuente más común de fanatismo. En el fanático las intuiciones pueden ser correctas, pero están mal utilizadas, porque se las respeta ciegamente. Lo que falta sobre todo es el pensamiento crítico.

Para explicarlo, Hare distingue dos niveles del pensamiento moral: a) los principios prima facie; $b$ ) el pensamiento crítico. Los principios, por sí mismos, tienen poca utilidad práctica, pues la actuación propiamente moral y autónoma consiste en el contraste inevitable entre los principios y los hechos

27 Norberto Bobbio, Il futuro della democrazia, Turín, Einaudi, 1984.

${ }_{28}$ R. M. Hare, «Fanaticism and Amoralism», Moral Thinking, Oxford University Press, pp. 169-187. 
que obligan siempre a contextualizar el principio y a interpretarlo. Dicho contraste es necesario porque, en la realidad, ningún principio o ningún derecho tiene un valor absoluto. El pensamiento crítico consiste, pues, en la única instancia capaz de resolver el conflicto que puede y suele darse entre los mismos principios cuando la defensa de uno de ellos parece ir inevitablemente en perjuicio de otro. Salvar la vida del paciente es un principio médico indiscutible, pero es un fanático el médico que lo convierte en un principio a ultranza sean cuales sean las circunstancias que rodean a la vida del paciente. Es decir, no es el contenido de los principios lo que hace fanática a una persona, sino su actitud ante los principios.

No es así como solemos verlo. Puesto que el fanático suele ampararse en una doctrina o una ideología determinadas, achacamos a la ideología o a la religión la causa del fanatismo. Tomamos el todo por la parte y consideramos que son el islamismo o la fe nacionalista sin más las causas de la acción fanática del terrorista. $\mathrm{O}$ atribuimos al catolicismo las posturas fundamentalistas ante el aborto o la eutanasia. Son explicaciones que quieren reducir la conducta fanática a los contenidos de determinadas creencias. Pero no es ésa la versión que da Hare de tales comportamientos, y creo que no se equivoca: no son las ideas lo que falla o lo que es intrínsecamente perverso, sino que el pensamiento se adhiera visceralmente y sin matices interpretativos a esas ideas.

Volvamos al problema del médico que antepone el valor de la vida del enfermo al valor, por ejemplo, de paliar el sufrimiento. Un fundamentalista es incapaz de comparar ambos principios, de ponerlos al mismo nivel para optar por uno o por otro. Piensa que optar por paliar el sufrimiento, administrando, por ejemplo, morfina y acelerando, en consecuencia, la muerte, equivale a negar de plano el valor fundamental de la vida. La suya es una visión rígida e inflexible de los principios. Por el contrario, el médico que prefiere que su paciente no sufra aun a costa de acortarle la vida no está negando el valor de la vida en general, sino, en todo caso, el valor de esa vida concreta que, en tales condiciones de sufrimiento, tal vez no merezca la pena vivirla. Cualquier opción sólo es generalizable si se piensa en casos muy similares o idénticos, no lo es si se piensa en abstracto. Por eso Kant sostenía que no podía haber conflicto entre principios, porque los pensó sólo en abstracto. Los hechos, sin embargo - matiza Hare-, nos dicen que el dilema no está entre una prescripción - salvar la vida - y una preferencia - evitar el sufrimiento-, sino entre dos prescripciones, puesto que todas las prescripciones son expresión de preferencias. Ninguna es, por sí misma, más moral que otra. Lo será cuando la elijamos como universalizable.

Aunque estoy, en principio, de acuerdo con la explicación de Hare, pienso al mismo tiempo que entender el fanatismo como una actitud inflexible ante los principios no explica del todo la cuestión. Creo que hay que insistir más en la utilización de medios inmorales, en el afán de destrucción que 
caracteriza la conducta del fanático. Éste no es sólo un ser inflexible, sino un nihilista, entendiendo por nihilismo no sólo la negación del bien común (que sería lo mismo que incurrir en el relativismo), sino la negación también del mal (que sería caer en el escepticismo). Es aceptar con todas sus consecuencias que «si Dios ha muerto, todo está permitido» ${ }^{29}$. Con la muerte de Dios desaparece asimismo la norma fundamental que es no hacer sufrir al otro. El nihilista no percibe el valor del sufrimiento ajeno.

Es ese desprecio absoluto por las vidas humanas y la aceptación del asesinato como medio lo que enturbia la defensa de cualquier causa que pudiera permanecer en la mente del fanático. La destrucción total, la aniquilación, se sobreponen de tal forma a cualquier idea o principio que, por buenos que éstos fueran en abstracto, acaban contaminándose de la perversidad que significa el terror. El medio se convierte en fin y el fin desaparece, puesto que ya no resiste la comparación con el medio. En los casos de terrorismo, la actitud nihilista es evidente. Pero también hay algo de eso en los casos de fanatismo fundamentalista, como el del médico del ejemplo antes mencionado. La actitud inflexible en defensa de un principio acaba conduciendo a la aniquilación propia o ajena, a la destrucción y negación de uno mismo o del otro sin más.

Luchar contra el fanatismo implica, en consecuencia dos cosas: 1) mostrar que la actitud de flexibilidad ante los principios es la única forma de acercarlos a la práctica; 2) rechazar radicalmente cualquier medio injusto o inmoral para lograr fines morales y justos. Ambos puntos, sin embargo, podrían parecer contradictorios y llevar a la siguiente deducción: si hay que ser flexible ante los principios, ¿por qué no aceptar, como muestra de tal flexibilidad, que cualquier medio puede acabar siendo legítimo? Una argumentación así no es infrecuente en nuestro tiempo. Por eso el fanático se impone: porque no le falta la fuerza moral para defender sus convicciones que sí le falta al postmoderno que se contenta con una «moralidad débil». Si el fanatismo es la adhesión tan firme a los principios que acaba en nihilismo, los no fanáticos hoy adolecen de pocas convicciones y de actitudes no siempre provistas de componentes críticos. La existencia y presencia del fanatismo entre nosotros tiene que hacernos revisar nuestra concepción de la tolerancia.

Dije en otro lugar que la tolerancia es la virtud básica de la democracia ${ }^{30}$. Hoy tengo más prevenciones ante semejante afirmación. Pues entiendo que la tolerancia puede ser - y de hecho está siendo - un obstáculo para la lucha contra el fanatismo. Lo está siendo, en primer lugar, porque es un valor formal que, en las democracias y Estados de Derecho, se da por supuesto, cuando la realidad es que los ciudadanos reaccionan con compor-

29 Así lo describe André Glucksmann en su, por lo demás, poco aprovechable libro Dostö̈evski à Manhattan, París, Éditions Robert Laffont, 2002.

30 Victoria Camps, Virtudes públicas, Madrid, Espasa, 1990, cap. 4. 
tamientos muy poco tolerantes ante lo que les resulta inesperado o incómodo. Las constantes respuestas xenófobas y racistas que provoca la inmigración demuestran que la regla de la tolerancia no está arraigada como disposición a aceptar al otro. La extrañeza que producen personajes como Le Pen sólo se explica porque habíamos dado por supuesto que el rechazo del otro no florece en los regímenes democráticos. Estamos viendo que no es así.

Pero es que, además, la afirmación a ultranza del valor de la tolerancia acaba confundiendo la actitud tolerante con la indiferencia. No importa lo que el otro haga, todo debe permitirse si de verdad queremos ser tolerantes. Pues lo no permisible ya está en el Código Penal, que es el compendio de la eticidad mínima. Un ejemplo más de la tendencia a reducir la moral a Derecho positivo. A diferencia de lo que decíamos del fanático, que no sabe flexibilizar los principios y las convicciones con actitudes críticas, el indiferente carece de convicciones o las tiene tan débiles que le falta fuerza para defenderlas. Nuevamente, la desmoralización. Una sociedad indiferente es una sociedad moralmente empobrecida.

La tolerancia conduce, así, a la ampliación casi ilimitada de lo moralmente aceptable. El temor al dogmatismo y a ser poco respetuosos con las diferencias llevan, por ejemplo, a Rawls a pensar que su propia teoría de la justicia tal vez sea «comprehensiva»y, por lo tanto, discutible. No quiero decir que no sea, efectivamente, una teoría comprehensiva, pura metafísica o pura ideología. Si no lo fuera, se explicaría mal la posición de Nozick, tan lejano ideológicamente a Rawls y tan cercano físicamente a él. Ahora bien, ¿qué tiene de malo sostener unas determinadas convicciones y tratar de defenderlas críticamente? La disposición excesiva a renunciar a lo conseguido como bueno o a tolerar lo ajeno, en realidad, muestra que tanto lo uno como lo otro nos son, en realidad, indiferentes. Eso ya no es tolerancia. Es indiferencia que revierte en desmoralización en el doble sentido de falta de contenidos morales y falta de fuerza moral. La debilidad de la conciencia tiene que ser suplida, entonces, con la fuerza de la ley.

Toynbee puso de manifiesto cómo el fin del fanatismo evidente en las guerras de religión, y que se sella en la paz de Westfalia, tuvo como móvil el cansancio: «El espíritu que condujo a la tolerancia fue un espíritu de desengaño, de miedo y de desprecio, y no de fe, de esperanza y de amor [...]. Una vez el ascua viva del fanatismo religioso se consumió en sus propias cenizas, el principio fundamental de la tolerancia cubrió rápida y sorprendentemente con hierba fresca el cristianismo endurecido de la Edad Moderna occidental. Pero también esa hierba [...] se secó tan pronto como prendió en el mundo el fuego aún más fuerte del fanatismo nacionalista [...]. Una tolerancia no enraizada en la fe no tiene ninguna fuerza en los occidentales, porque la naturaleza humana no es capaz de soportar el vacío» ${ }^{31}$. Un vacío, en

31 A. Toynbee, Krieg und Kultur, 1950, pp. 14 ss. Citado por José Bada en La tolerancia, entre el fanatismo y la indiferencia, Editorial Verbo Divino, 1996. 
efecto, que, tras la secularización y el laicismo, sólo puede y debe ser llenado por la ética, si no queremos echar mano de pseudorreligiones, como los nacionalismos. Ahora bien, dado que la ética es todo lo que tenemos, ¿cómo mantener la fe en sus principios? La tolerancia no puede ser un simple modus vivendi, una tolerancia formal que confía en las instituciones - finalmente en el Derecho - como árbitros de nuestras disputas morales, o como los espacios que sustituyen a un vacío deliberativo. No me parece satisfactoria la tesis de John Gray ${ }^{32}$ de que el liberalismo no es un sistema de principios universales, sino «la empresa de buscar modos de coexistencia entre diferentes maneras de vivir». Por muchos que sean los conflictos de valores, debe darse un núcleo de creencias básicas, eso que Ernesto Garzón Valdés ha denominado «cotos vedados». Hay que poder distinguir entre aquellos modelos y formas de vivir o de gobernar aceptables y otras maneras de hacer claramente irracionales, inhumanas ${ }^{33}$.

En aras de poder separar lo racional de lo irracional no hay que menospreciar el hecho de que las posturas fanáticas, si bien no son justificables, sí son explicables. Conocer las causas de las cosas es el primer paso para abordarlas racionalmente. Además de consistir en actitudes inflexibles y en la utilización de medios violentos y asesinos, el fanatismo remite a unas causas o a unas condiciones que sin duda le dan vida. Causas externas, pero también internas, intrínsecas al propio sujeto, ya que no todos los que viven bajo determinadas condiciones reaccionan con la misma falta de sensibilidad de que hace gala el fundamentalista. En tal sentido, Adorno señala que apelar a valores eternos no les dice nada a los criminales. «Lo urgente y necesario es [...] el viraje al sujeto. Hay que sacar a luz los mecanismos que hacen a los seres humanos capaces de tales atrocidades; hay que mostrárselos a ellos mismos y hay que tratar de impedir que vuelvan a ser de este modo, a la vez que se despierta una conciencia general sobre tales mecanismos. Los asesinados no son los culpables, ni siquiera en el sentido sofístico y caricaturesco en que muchos quisieran presentarlo hoy. Los únicos culpables son los que sin miramiento alguno descargaron sobre ellos su odio y agresividad. Esa insensibilidad es la que hay que combatir; las personas tienen que ser disuadidas de golpear hacia fuera sin reflexionar sobre sí mismas. La educación sólo podría tener sentido como educación para la autorreflexión crítica» ${ }^{34}$.

Todo nos lleva de nuevo a la necesidad de no cejar en el empeño de mantener un ethos, entendido como la costumbre, lo habitual, lo habitado por los humanos. Mantenerlo y, sobre todo, alimentarlo. Más que la nostalgia de comunidad que expresan los comunitaristas, deberíamos sentir nostalgia de

32 John Gray, Las dos caras del liberalismo. Una nueva interpretación de la tolerancia liberal, Barcelona, Paidós, 2001.

33 Ernesto Garzón Valdés, «Representación y democracia», en Derecho, ética y política, Madrid, Centro de Estudios Constitucionales, 1993, pp. 631-650. Y también «Instituciones suicidas», (Segundas Conferencias Aranguren), en Isegoría, núm. 9 (1994), pp. 64-128.

34 Theodor W. Adorno, Educación para la emancipación, Madrid, Morata, 1998, pp. 80-81. 
ciudad en el sentido griego de la polis. No tanto por su valor comunitario como por estar fundada en la doxa, en la pluralidad de puntos de vista, tratando de evitar tanto la anarquía como la aristocracia. En la ciudad cabe el error, la duda, el ensayo, en cambio se excluyen las posturas inflexibles y fanáticas, que no se atienen a vivir de acuerdo con las dos virtudes mínimas (recordemos el mito de Prometeo contado por Protágoras en el diálogo platónico que lleva su nombre): el sentido moral y la justicia.

La búsqueda del bien común, la construcción de una identidad moral, la tolerancia no indiferente, son de nuevo expresiones de esa autonomía que es, desde la antigüiedad, el principio y el fin de la ética. Las dificultades por encontrar el bien común, la identidad moral, la tolerancia no indiferente nos están diciendo que el gran problema moral de nuestro tiempo radica en la invención de la libertad. Pues, en efecto, la libertad individual sólo se realiza en la colectividad, es un proyecto colectivo. Un proyecto que consiste en trascender el interés particular a favor del interés común. El paso decisivo hacia la autonomía, según Castoriadis, se dio cuando los griegos empezaron a preceder sus leyes con el preámbulo edoxe te boule kai to demo («parece buena para la asamblea y para el pueblo»). No decían «es buena», sino «parece». Pues la autonomía no llega a desarrollarse donde sólo hay certezas. La autonomía es un fin y una cierta guía, no nos resuelve situaciones reales y concretas. Una sociedad autónoma es una sociedad de individuos que se «autoconstituyen», que no tienen una identidad predeterminada, sino que se enfrentan a una tarea constante de «identificación». Así, «es necesario recomenzar el interrumpido discurso del bien común, algo que hace que el bien común sea factible y que valga la pena luchar por él» ${ }^{35}$.

La preocupación por la libertad individual conduce directamente a la preocupación por las condiciones de la sociedad. Interesarse por la propia autonomía no debe discurrir al margen del interés por la prosperidad de una cultura común. «El temor a la uniformidad y a la negación de la autonomía individual ha llevado a muchos autores liberales a insistir en que el Estado debería ser totalmente ajeno a la promoción de los ideales de una buena vida. Esto a su vez ha llevado al empobrecimiento de su concepción de la prosperidad humana y de las relaciones entre el bienestar individual y la cultura común. Por el contrario, deberíamos denunciar el rechazo de la autonomía y el apoyo a la uniformidad como concepciones erróneas del bienestar individual. Sólo a través de concepciones del bienestar basadas en la autonomía y en el pluralismo de valores podemos restaurar la verdadera concepción de la moral en la política» ${ }^{36}$.

El temor liberal a la uniformidad y al dogmatismo, el laissez faire generalizado no sólo congelan el pensamiento, sino consolidan la atomización social e impiden la «moralización» de la vida en común. Quedan las normas

35 Zygmut Bauman, En busca de la política, México, Fondo de Cultura Económica, 2001, pp. 146 y 117.

36 Joseph Raz, La ética en el ámbito público, Barcelona, Gedisa, 2001, p. 130. 
positivas, el Derecho, pero la entrega irreflexiva a las normas lleva, en el mejor de los casos, a la apatía y a la desgana y, en el peor, al fanatismo. Sea como sea, el sujeto moral abdica de su condición. El reto que tiene la ética del siglo XXI es no cejar en el empeño de buscar el bien aun a sabiendas de que no contará con la seguridad de haberlo encontrado. Es el aliento que transmite Berlin al final de «Dos conceptos de libertad» cuando nos dice: «Darse cuenta de la validez relativa de las convicciones de uno y, sin embargo, defenderlas sin titubeo, es lo que distingue al hombre civilizado de un bárbaro» ${ }^{37}$.

${ }^{37}$ Isaiah Berlin, Cuatro ensayos sobre la libertad, Madrid, Alianza Editorial, p. 243. 